findings of impaired activity of aryl hydrocarbon hydroxylase in the liver and small bowel of patients with psoriasis. ${ }^{2}$

The salivary clearances indicate that the inducing effect of smoking on antipyrine metabolism is similar in patients and normal subjects. This contrasts with our observations in skin: so far we have been unable to show any difference in skin activity of aryl hydrocarbon hydroxylase between smokers and non-smokers, and in-vitro induction with benzanthracene of aryl hydrocarbon hydroxylase activity in lesion-free skin of patients with psoriasis is only about $50 \%$ of normal. ${ }^{1}$ Clearly, in-vivo induction by smoking as measured by antipyrine clearance is not analogous to in-vitro induction by benzanthracene as measured by activity of aryl hydrocarbon

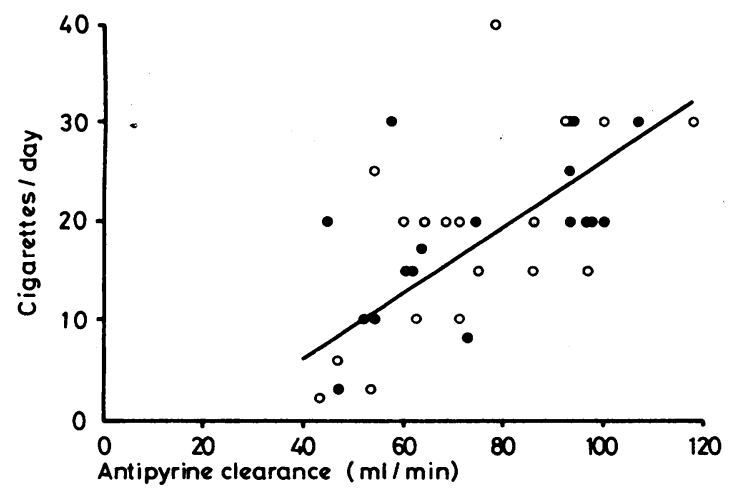

Correlation between antipyrine clearance and cigarette consumption in normal controls $(\Theta)$ and patients with psoriasis $(0)$.

hydroxylase. We do not know whether these observations are due to different control mechanisms regulating skin and hepatic monooxygenases, tissue-specific differences in the multiple forms of the cytochromes in microsomal mono-oxygenases, or access of inducing substances into the epidermis.

Our observations have broader implications. Firstly, since psoriasis is common it contributes to the wide individual variation in the rate of microsomal oxidation of drugs. Non-smokers with psoriasis may have exaggerated pharmacological responses to some drugs inactivated by microsomal oxidation, ${ }^{4}$ while smokers with psoriasis may be at greater risk from carcinogens. Secondly, the observations provide in-vivo evidence that impairment of mono-oxygenase activity ${ }^{1}{ }^{2}$ is not confined to skin. ${ }^{2}$ Unlike salivary antipyrine clearance, 4-hydroxylation of debrisoquine is unchanged in psoriasis, ${ }^{5}$ suggesting that the defect is found in only some of the cytochromes concerned with microsomal oxidation. This evidence that the enzyme defect is specific and widespread supports the view that it may be close to the genetic abnormality of psoriasis. ${ }^{2}$

This study was supported by MRC Programme Grant No 419187.

1 Chapman PH, Rawlins MD, Shuster S. The activity of aryl hydrocarbon hydroxylase in psoriatic skin. Lancet 1979 ;i:297-8.

2 Chapman PH, Kersey PJ, Keys B, Shuster S, Rawlins MD. Generalised tissue abnormality of aryl hydrocarbon hydroxylase in psoriasis. $\mathrm{Br}$ Med F 1980;281:1315-6.

3 Fraser HS, Mucklow JC, Murray S, Davies DS. Assessment of antipyrine kinetics by measurement in saliva. Br f Clin Pharmacol 1976;3:321-5.

4 Rawlins MD, Thompson JW. Pathogenesis of adverse drug reactions. In: Davies DM, eds. Textbook of adverse drug reactions. Oxford: Oxford University Press, 1977:10-31.

${ }^{5}$ Chapman PH, Idle JR, Mahgoub A, et al. 4-hydroxylation of debrisoquine in psoriasis. Br f Clin Pharmacol 1980;9:113-4P.

(Accepted 4 November 1980)

Department of Pharmacological Sciences, Wolfson Unit of Clinical Pharmacology, University of Newcastle upon Tyne, Newcastle upon Tyne NEI TRU

P H CHAPMAN, BSC, PHD, Janssen lecturer

BARBARA KEYS, technician

M D RAWLINS, MD, FRCP, professor

Department of Dermatology, University of Newcastle upon Tyne CELIA MOSS, MRCP, research registrar

SAM SHUSTER, PHD, FRCP. professor

\section{Multicentre prospective trial of Silastic foam dressing in management of open granulating wounds}

Silastic foam was first used as a wound dressing after the excision or laying open of a pilonidal sinus. ${ }^{1}$ When compared retrospectively with a moistened gauze pack it appeared to have certain advantages. Its use in various open granulating wounds was subsequently recorded. ${ }^{2}$ We report a multicentre study in which these apparent advantages were subjected to the closer scrutiny of a randomised trial.

\section{Patients, methods, and results}

The wound remaining after excision of a pilonidal sinus was again chosen for study. Pilonidal sinus occurs mainly in young and otherwise healthy people, and the surgical technique is readily standardised. Each wound was packed for four days with a gauze roll soaked in flavine emulsion. This was then removed, the wound measured, and the patient randomised to receive either a Silastic foam dressing, refashioned at weekly intervals, or daily packing with gauze soaked in a $0.5 \%$ aqueous solution of chlorhexidine (Hibitane).

When discharged from hospital patients were asked to record the number of occasions on which a visit by a district nurse was necessary and the degree of discomfort that they experienced each time the dressing was changed (extreme 3, moderate 2 , mild 1, none 0 ). All patients were reviewed weekly and the time taken for each wound to arrive at a stage where packing was no longer required to prevent bridging of the wound edges noted. The wound was considered to have healed when its surface was completely epithelialised.

Eighty patients were followed up to complete healing. The table shows the relative merits of the two dressing techniques. There were no appreciable differences in the rates of healing in either group. Duration of hospital stay

Effect of dressings on healings. (Figures are means $\pm S D$ )

\begin{tabular}{|c|c|c|}
\hline & $\underset{(n=44)}{\text { Foam dressing }}$ & $\begin{array}{c}\text { Gauze packing } \\
(\mathrm{n}=36)\end{array}$ \\
\hline $\begin{array}{l}\text { Wound volume (ml) } \\
\text { No of days packed } \\
\text { No of days to complete healing } \\
\text { Duration of hospital stay (days) } \\
\text { Work lost (days) } \\
\text { No of home nursing visits ... }\end{array}$ & $\begin{array}{lr}\therefore & 59 \\
\because & 41.5 \pm 57 \cdot 7 \\
\because & 66.2 \pm 26.2 \\
\because & 8.5 \pm 12.3 \\
\because & 38.6 \pm 24.9 \\
\therefore & 4.6 \pm 1.5\end{array}$ & $\begin{array}{l}64 \pm 74 \cdot 5 \\
41 \cdot 8 \pm 26 \cdot 7 \\
57 \cdot 7 \pm 19 \cdot 6 \\
7 \cdot 3 \pm 6 \cdot 2 \\
45 \cdot 4 \pm 19 \cdot 9 \\
35 \cdot 1 \pm 17 \cdot 4\end{array}$ \\
\hline
\end{tabular}

and time lost from work were similar. The demands made on the district nursing service were considerably reduced in those patients managed with the foam dressing. The degree of discomfort experienced when the dressing was changed in the first week was obtained by dividing the total score for that week by the number of dressing changes undertaken. Thus patients in whom the foam dressing was used experienced only mild discomfort (mean \pm SD 1.4 \pm 0.6 units), while those whose wounds were packed with moistened gauze noted moderate to severe discomfort (2.9 $\pm 2 \cdot 6$ units).

\section{Comment}

The efficiency and continuity of healing in an open granulating wound must not be adversely affected by contamination of the wound with particulate or flbrous material or, when the dressing is changed, by adhesions causing disruption of the delicate capillaries in the newly formed granulations. An ideal dressing should therefore be fibre fast, particulate free, and non-adherent and yet retain an absorptive capacity. ${ }^{3}$ Silastic foam dressing approaches this ideal: it has no fibre or particulate matter to shed, it readily conforms to wound contours, and it is non-adherent while absorptive. Despite these advantages the wounds dressed with Silastic foam did not heal more quickly than those managed with a moistened gauze pack, as had been suggested in the earlier retrospective study. ${ }^{1}$ This discrepancy may be accounted for by the unreliable nature of data collected by a retrospective search of case notes. Possibly the theoretical advantages of Silastic foam dressings attain greater practical importance in debilitated subjects in whom wound healing may already be compromised. Silastic foam dressing, however, has undoubted advantages for the nurse, purse, and patient. It is inexpensive and far less demanding of skilled nursing care. The patient quickly learns to change his own dressing, experiencing only mild discomfort when doing so. Moreover, increasing confidence has led 
to a shortened hospital stay in the two centres most familiar with the techniques.

1 Wood RAB, Hughes LE. Silicone foam sponge for pilonidal sinus: a new technique for dressing open granulating wounds. Br Med $\mathcal{f} 1975$; iv: $131-3$.

2 Wood RAB, Williams RHP, Hughes LE. Foam elastomer in the management of open granulating wounds: experience with 250 patients. Br f Surg 1977;64:554-7.

3 Turner TD. Hospital usage of absorbent dressings. Pharmaceutical fournal 1979;221:421-2.

(Accepted 4 November 1980)

Department of Surgery, Welsh National School of Medicine, Cardiff

R H P WILLIAMS, FRCs, research fellow (now senior registrar, Newcastle upon Tyne)

Ninewells Hospital, Dundee

R A B WOOD, FRCS, MRCP, senior lecturer in surgery

Singleton Hospital, Swansea

M C MASON, FRCs, consultant surgeon

York District Hospital, York

M EDWARDS, FRcs, surgical registrar

Derbyshire Royal Infirmary, Dexby

P GOODALL, MGHI, FRCs, consultant surgeon

\section{Systemic Haemophilus influenzae and facial cellulitis in infants}

Haemophilus influenzae is a well-recognised cause of serious infections, common manifestations including meningitis, epiglottitis, and pneumonia. ${ }^{1}$ Facial cellulitis is an uncommon but characteristic presentation, ${ }^{23}$ but has not been described from Britain. Its early clinical recognition is especially important because of associated bacteraemia. We describe four such cases seen within nine months in Cardiff.

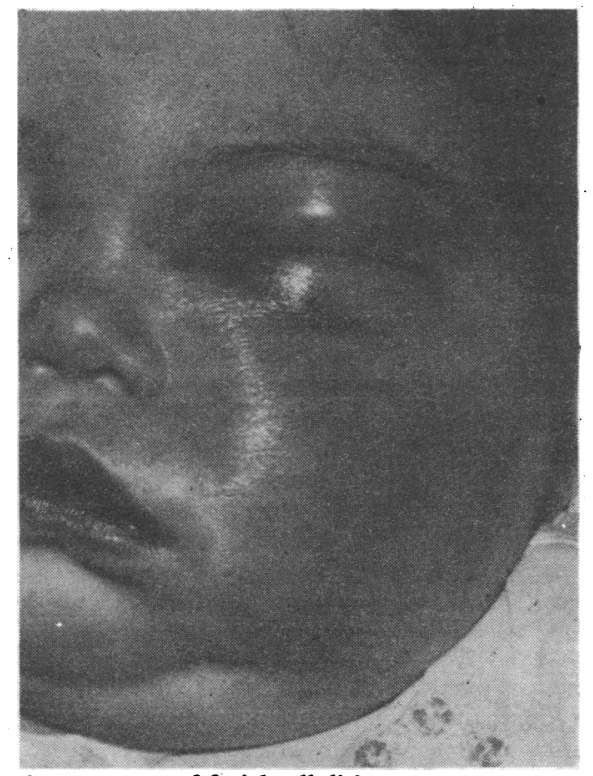

Appearances of facial cellulitis.

\section{Patients, methods, and results}

Three boys and one girl aged 7-9 months presented with swelling of the cheek for periods ranging from six to 48 hours. All had been in good health, although one had been treated for otitis media two weeks before. On examination they looked toxic and had high temperatures of $39-40^{\circ} \mathrm{C}$. In all cases the affected cheek was grossly swollen, indurated, and bluish. Three had an associated otitis media. Investigations disclosed a polymorph leucocytosis, and $H$ influenzae was subsequently isolated on blood cultures in each case. All were treated with parenteral ampicillin and made a satisfactory recovery.

\section{Comment}

Facial cellulitis has characteristic features and usually occurs in very young children. The swelling develops within hours, has a bluish hue, and is accompanied by a brisk fever and leucocytosis. Blood cultures show an associated bacteraemia. Recognising the clinically characteristic pattern is important if possible complications of the bacteraemia are to be prevented.4

It is difficult to explain why this infection should localise in the cheek. In our patients the cellulitis was not related to the parotid gland or duct, and no oral lesion was seen. Alternatives to local infection are lymphatic ${ }^{5}$ or haematogenous spread, but we found no common features in these four children to suggest these. We subsequently saw a 10-month-old infant with $H$ influenzae cellulitis at the right elbow and left ankle: simultaneous infection in these two sites must have occurred by the haematogenous route.

The absence of other British reports suggests that the condition may have escaped notice in the past or may be evidence of changing virulence of $H$ influenzae. It will be interesting to see if further cases will be reported.

We thank Dr R C Evans and Dr E R Verrier Jones for permission to report on two cases, and Miss T Butler and Mrs J H Bosley for secretarial work.

Requests for reprints should be sent to Dr J F Murphy.

${ }^{1}$ Dajani AS, Asmar BI, Thirumoorthi MC. Systemic Haemophilus influenzae disease: an overview. $\mathcal{F}$ Pediatr 1979 ;94:355-64.

2 Green M, Fousek MD. Haemophilus influenzae type B cellulitis. Pediatrics 1957;19:80-3.

${ }^{3}$ Feingold M, Gellis SS. Cellulitis due to Haemophilus influenzae type B. $N$ Engl F Med 1965;272:788-9.

4 Marshall R, Teele DW, Klein JO. Unsuspected bacteraemia due to Haemophilus influenzae: outcome in children not initially admitted to hospital. $\mathcal{F}$ Pediatr 1979;95:690-5.

5 Nelson JD, Ginsburg CM. A hypothesis on the pathogenesis of Haemophilus influenzae buccal cellulitis. F Pediatr 1976;88:709-10.

(Accepted 8 October 1980)

Department of Child Health, University Hospital of Wales, Heath Park, Cardiff CF4 4XN

A R J BOSLEY, MRCP, DCH, senior registrar

J F MURPHY, MRCP, DCH, senior registrar

J A DODGE, MD, FRCP, reader in paediatrics

BEANS. Both the garden and field beans are so well known, that it saves me the labour of writing any description of them. The virtues follow.

They are plants of Venus, and the distilled water of the flower of garden beans is good to clean the face and skin from spots and wrinkles, and the meal or flour of them, or the small beans doth the same. The water distilled from the green husk, is held to be very effectual against the stone, and to provoke urine. Bean flour is used in poultices to assuage inflammations arising from wounds, and the swelling of women's breasts caused by the curdling of their milk, and represses their milk; Flour of beans and Fenugreek mixed with honey, and applied to felons, boils, bruises, or blue marks by blows, or the imposthumes in the kernels of the ears, helps them all, and with Rose leaves, Frankincense and the white of an egg, being applied to the eyes, helps them that are swollen or do water, or have recieved any blow upon them, if used with wine. If a bean be parted in two, the skin being taken away, and laid on the place where the leech hath been set that bleeds too much, stays the bleeding. Bean flour boiled to a poultice with wine and vinegar, and some oil put thereto, eases both pains and swelling of the privities. The husk boiled in water to the consumption of a third part thereof, stays a lask; and the ashes of the husks, made up with old hog's grease, helps the old pains, contusions, and wounds of the sinews, the sciatica and gout. The field beans have all the aforementioned virtues as the garden beans.

Beans eaten are extremely windy meat; but if after the Dutch fashion, when they are half boiled you husk them and then stew them (I cannot tell you how, for I never was a cook in all my life) they are wholesome food. (Nicholas Culpeper (1616-54) The Complete Herbal, 1850.) 